\title{
QUANDO A INDÚSTRIA SE TRANSFORMA... atores locais e políticas subnacionais de eqüidade de gênero e raça
}

\author{
Nadya Araujo Guimarães
}

Resumo: O artigo argumenta sobre a pertinência das iniciativas de coordenação de atores, em torno de políticas locais, para enfrentar os efeitos da reestruturação das firmas sobre a desigualdade de gênero e de raça. Analisa o caso do $\mathrm{ABC}$ paulista, nos anos 90 , quando o mercado de trabalho foi reorganizado e os padrões de inclusão de trabalhadores negros e mulheres foram redefinidos, suscitando possibilidades diversas de políticas voltadas à eqüidade.

Palavras-chave: mercado de trabalho; desigualdade; políticas de eqüidade.

Abstract: This article deals with the pertinence of the initiatives of coordinating the agents around local politics in order to face the effects of companies' restructuring on the gender and race inequality. It analyses the case of ABC in São Paulo in the 90's, when the labor market was reorganized and the rules of inclusion of AfroBrazilian and women were redefined, what stimulated several possibilities of creating equity politics.

Key words: labor market; inequality; equity politics.

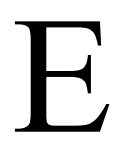

ste artigo procura alinhar e socializar reflexões desenvolvidas sob o estímulo de uma iniciativa especial: a da condução de um experimento de pesquisa que aliou investigação, animação de atores e construção de uma agenda de intervenção voltada para minimizar os efeitos da reestruturação das empresas sobre as dificuldades de inclusão de trabalhadores negros e mulheres na região do $\mathrm{ABC}$ paulista, coração industrial do Brasil. ${ }^{1}$

A reflexão desenvolvida aqui tem alguns pontos de partida em comum com a forma como, no Brasil, é analisado o processo de mudança na estrutura produtiva e nas formas de uso do trabalho que se intensificou nos anos 90. São explicitados, de modo a deixá-los assentes.

Em primeiro lugar, o reconhecimento de que, notadamente a partir do início daquela década - quando se associaram crise, ajuste macroeconômico e intensas transformações microorganizacionais - um célere processo de reestruturação industrial teve lugar no país, atingindo em cheio alguns dos setores industriais que, até então, haviam sido os carros-chefe da economia nacional.

Em segundo lugar, o entendimento de que, no curso dessa reestruturação, alteraram-se as práticas de emprego e a dinâmica das relações industriais. A chamada "racionalização do trabalho" e o movimento em direção a formas ditas "flexíveis", tendo lugar num contexto de crescimento pífio (quando não nulo) e de inflação controlada, plasmaram novos interesses e alteraram o conteúdo das negociações entre gerências e trabalhadores, trazendo à tona formas institucionais novas, em que se aninhavam interesses antes insuspeitados. ${ }^{2}$

Em terceiro lugar, o reconhecimento de que tais mudanças afetaram significativamente o plano da organização industrial. E elas não somente instituíram novos formatos para as relações entre firmas, para a coordenação de esforços num contexto de desverticalização crescente, como também pareceram ameaçar o próprio padrão de distribuição espacial da atividade industrial que até então 
prevalecera. O movimento de fusões e aquisições que caracterizou a primeira parte da década dos 90 alterou a configuração de cadeias produtivas, globalizando-as, e abriu, simultaneamente, caminho para o desenraizamento dos investimentos. A profusão dos incentivos fiscais e financeiros, adotados por instâncias subnacionais em competição, aprofundou o processo de relocalização das novas plantas produtivas, desafiando justamente a centralidade daquela região que fora o coração industrial da economia brasileira - adjacente à capital paulista, chamada região do $\mathrm{ABC}$. Ali havia se concentrado, nas décadas de ouro do processo de substituição de importações (50-70), o grosso dos investimentos manufatureiros e, ainda hoje, é o $\mathrm{ABC}$ responsável pela maior parcela do produto bruto gerado pela indústria no Brasil.

Importantes mudanças tiveram lugar na estrutura do mercado de trabalho da região do Grande ABC no curso dos anos 90, como parte do processo de intensa reestruturação produtiva por que passavam as firmas ali localizadas. Tais mudanças apresentaram um caráter fortemente seletivo. Se essa seletividade foi fartamente estudada no que concerne às firmas e suas estratégias, o mesmo não se poderia dizer no que respeita aos trabalhadores, especialmente quando observados não do ponto de vista de qualificação, escolaridade ou tempo de emprego, mas a partir da sua condição de gênero e raça. No entanto, essas mudanças afetaram de maneira fortemente diferencial negros e brancos, homens e mulheres, algumas vezes consolidando tendências; outras, redefinindo padrões de desigualdade.

Até então, as instituições de planejamento e desenvolvimento regional haviam avançado em políticas públicas, em especial para estimular e enraizar investimentos, bem como para capacitar atores locais ao melhor desempenho em contextos onde não raramente as estratégias competitivas eram definidas por parâmetros supranacionais. ${ }^{3}$ Cabe, agora, desenvolver políticas voltadas ao mercado de trabalho, atacando a seletividade social da intensa reestruturação, que atingiu de modo desigual os trabalhadores(as).

Interlocutores mais apressados manifestam, com freqüência, a sua descrença na possibilidade de que efeitos de uma intensa transformação macroestrutural possam ser enfrentados com políticas públicas de âmbito subnacional. A desproporcionalidade de escala ao confrontar a origem do problema e as vias de sua solução (ou atenuação) parece ser um argumento de primeira hora para retirar da política e da gestão locais as chances de intervir sobre os fenômenos. Aqui, ao contrário, pretende-se reunir evidên- cias de que as novas formas de seletividade e de desigualdade no trabalho, embora promovidas por fatores de âmbito nacional e supranacional e resultantes de processos intensos de mudança macroeconômica, poderiam ser contra-arrestadas (ou, quando menos, paliadas) por meio de políticas públicas de âmbito subnacional ou intra-regional. ${ }^{4}$ Se mais não fosse, porque os padrões da intensa mobilidade ocupacional ocorrida na região não tiveram como correlata uma igualmente elevada mobilidade em direção a melhores oportunidades ocupacionais que se localizassem fora do ABC.

Nem fuga de capitais nem fuga de trabalhadores, esse é o ponto de partida do argumento. Assim sendo, ganham importância as questões do que se passou a referir como governança subnacional. Por isso mesmo, procura-se defender a pertinência das iniciativas de coordenação de atores em torno de políticas de âmbito local em face de um tal tipo de desafio. E, nisso, o ABC se constitui num terreno fértil e num caso relevante. De fato, a força centrípeta de atores locais e regionais forjou ali uma história de intensa interação e um tecido institucional (local e regional) de significativa complexidade..$^{5} \mathrm{Na}$ conjuntura dos anos 90, o senso comum dos intérpretes advertia que era justamente esse tecido institucional que parecia estar sendo ameaçado pelos efeitos centrífugos da nova geografia dos investimentos, nas condições do arranjo entre forças globais em busca de implantações locais. O ABC mostrava-se, então, um bom exemplo, por se superporem diversas formas de seletividade (espacial, de firmas e de trabalhadores); a partir dele seria possível refletir sobre os elos entre mudança nos padrões de desenvolvimento e nas formas de coordenação dos agentes (e, nesse sentido, de governança), por um lado, e efeitos de tal mudança no que tange aos problemas de eqüidade no trabalho, notadamente quanto à inserção econômica de negros e de mulheres, por outro.

Para empreender tal reflexão, organiza-se o argumento em duas partes. Na primeira, ilustra-se a importância das mudanças ocorridas na região, na década de 90 , destacando, com base na literatura disponível, que foi no mercado de trabalho (e não no tecido industrial, como a princípio se imaginou) que tiveram lugar os efeitos mais radicais dessa modificação. Por isso mesmo, observamse dois aspectos-chave da organização do mercado de trabalho: por um lado, a transformação na estrutura do emprego formal (visível na radical redivisão dos "bons empregos" entre os setores da atividade econômica, notadamente entre indústria e serviços); por outro lado, a al- 
teração no padrão do desemprego (com uma notável ampliação do seu volume e dos riscos de perda do trabalho regular).

$\mathrm{Na}$ segunda parte, procura-se demonstrar que tais mudanças têm implicações importantes para as formas e as políticas públicas voltadas à inclusão das chamadas "minorias" (homens negros, mulheres brancas e negras), pois fazem com que o risco do desemprego atinja desigual e seletivamente os homens e mulheres e com que a sobrevivência nos postos de trabalho seja também seletiva e importe na reprodução de desigualdades de distintas espécies. Por isso, uma investigação mais cuidadosa dos fatores explicativos das desigualdades procurará retirar primeiras conseqüências da análise para uma agenda de políticas públicas. Para tanto, busca-se identificar de maneira estatisticamente rigorosa padrões de desigualdade que especificariam as diferenças salariais entre homens negros, mulheres brancas e mulheres negras vis-à-vis os homens brancos, no mercado de trabalho da região do Grande $\mathrm{ABC}$. Isso porque se não se identificam padrões e, nestes, os componentes principais das desigualdades, não é possível saber como desenhar e onde localizar as políticas que atuem sobre os fatores que atingem tais minorias, desigualando-as.

Ora, exatamente nesse ponto o interesse de pesquisa diferencia-se, em boa medida, das temáticas que atraíram o mainstream dos estudos brasileiros sobre traba1ho. De fato, ao longo dos anos 90, a sociologia brasileira esteve voltada para a caracterização primordialmente do que se passava em três domínios: as configurações ocupacionais que surgiam nos ambientes reestruturados; as novas práticas de emprego e formas de tessitura das relações industriais nas cadeias produtivas emergentes e globalizadas; a produção de novos padrões de coordenação de ações entre firma, clusters e Estado (ou outros agentes da regulação pública). O que aqui se aborda diz respeito a uma outra face desse processo: não tanto os mecanismos e formas de coordenação entre diversas instâncias nacionais e subnacionais num contexto de intensa globalização, mas o destino dos que são tornados (ou podem vir a tornar-se) "redundantes" e o lugar que vem sendo ocupado (ou que pode vir a ser ocupado) pela coordenação de ações locais, regionais e nacionais visando políticas que, ao aumentarem as chances de segmentos sociais mais vulneráveis, permitam trazer para a frente da cena das atuais mudanças o desafio de conciliar desenvolvimento, competitividade e eqüidade.

\section{REESTRUTURAÇÃO PRODUTIVA E MUDANÇAS NO MERCADO DE TRABALHO DO GRANDE ABC: ALGUMAS EVIDÊNCIAS}

Um intenso processo de reestruturação produtiva atingiu os principais setores da atividade econômica no Grande $\mathrm{ABC}$ ao longo da década de 90 . De fato, aquela região que fora até os anos 80 o coração industrial da atividade econômica, constituindo o mais sólido dentre os brownfields em que se organizava o tecido industrial brasileiro, viu-se desafiada pelos custos econômicos da abertura comercial rápida, sob condições de intensa crise econômica interna, num contexto de profunda transformação dos instrumentos de regulação que haviam marcado a presença do Estado na economia brasileira. Os setores-chave que caracterizavam a vocação produtiva regional - isto é, a indústria e nesta os segmentos automobilístico e químico - foram fortemente atingidos, seja pelas políticas de abertura, seja pelas respostas que foram postas em ação pelas empresas ali instaladas (ou pelas que vieram a se instalar) no processo de intensa internacionalização das cadeias produtivas locais.

Como resultado dessa mudança, os anos 90 mostram uma tendência clara à redivisão do papel dos grandes setores da atividade produtiva no que tange à sua capacidade de gerar empregos formais. ${ }^{6}$

\section{GRÁFICO 1}

Evolução do Emprego Formal, segundo Setor de Atividade Região do Grande ABC - 1989-00

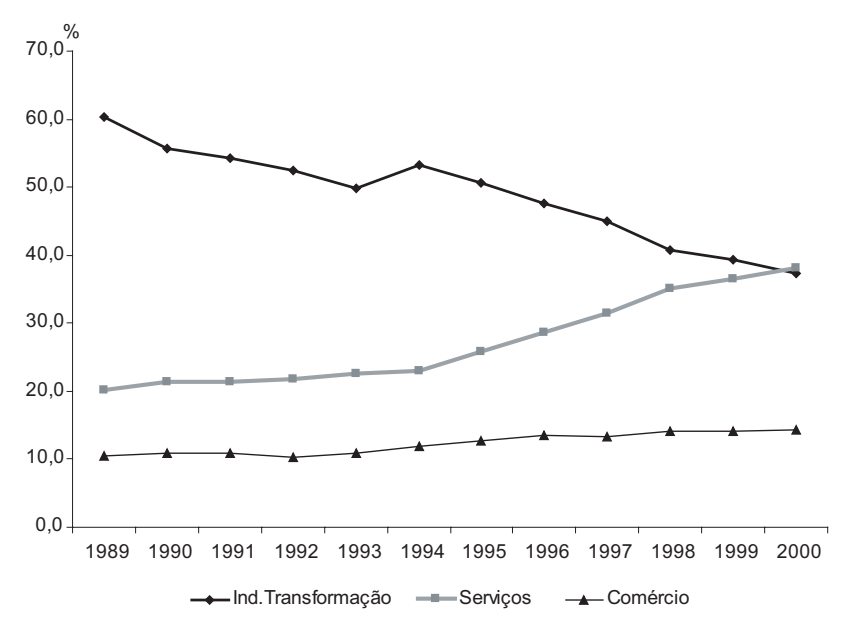

Fonte: MTE. Rais. Processamentos próprios. 
Tal redivisão fica patente no Gráfico 1. A indústria que, em 1989, responsabilizava-se por 6 em cada 10 empregos formais criados na região (três vezes mais do que os serviços, que criavam 2 postos, e seis vezes mais do que o comércio, que gerava apenas 1 em cada 10 postos), chega a 2000 em igualdade de condições com os serviços (cada qual gerando pouco mais que 3 em cada 10 postos formais de trabalho). De fato, a sangria de postos formais de trabalho verificada em média na região do $\mathrm{ABC}$ (que se reduzem de 602.004, em 1989, para 511.787, em 2000) é explicada pelo enorme encolhimento de empregos que ocorre na indústria (de 363.333 para 191.998); isso porque serviços e comércio (aquele mais do que este) têm, ambos, ganhos em termos de postos criados nesses 12 anos.

Diante de tamanha recomposição, dois tipos de interpretação foram produzidos, com conseqüências absolutamente díspares no que concerne às políticas públicas. Levando em conta a intensidade com que se perdiam postos na indústria e, aliando-se a isso o movimento de reespacialização da atividade produtiva então em curso, com exemplos de novas plantas industriais instalando-se fora da região do $\mathrm{ABC}$, abriu-se caminho para a hipótese que delineava um processo de desindustrialização da região. Tal processo acabaria por mudar a vocação econômica regional, tornando-a, como toda a Região Metropolitana de São Paulo, uma concentração metropolitana de inclinação terciária. Em que pese o apelo que esse argumento pareceu exercer sobre a opinião pública e a imprensa e mesmo sobre certos segmentos da academia e do governo, novas informações produzidas ${ }^{7}$ apontavam em sentido diverso, atraindo a atenção para achados desconcertantes ao senso comum da época.

De fato - e na contramão do que supunha o argumento da desindustrialização -, em 1996, a região do ABC mantinha-se firme no que tange à sua participação na estrutura industrial do Estado de São Paulo, sobretudo nos setores mais intensivos em capital. ${ }^{8}$ Ademais, sua vantagem comparativa vinha justamente do fato de concentrar empresas de grande conteúdo tecnológico em maior proporção que outras regiões. Isso equivale a dizer que, ao longo dos anos 90, um intenso processo de reestruturação produtiva, de atualização tecnológica e de modernização organizacional teve lugar entre as empresas industriais da região, em especial entre aquelas de grande porte, justamente as que dão a tônica e formam o grosso do valor da produção nesse cinturão industrial brasileiro.

$\mathrm{E}$, se algumas plantas industriais abandonaram a região, notadamente em direção ao interior do Estado de São Paulo, as que ali restaram se consolidaram com investimentos maciços; mais ainda, marcharam para aumentar o seu conteúdo tecnológico e de conhecimento. ${ }^{9}$ Entretanto, esse mesmo processo, responsável por manter o posto do ABC no quadro da economia paulista, exacerbou a pressão no sentido do enxugamento fortemente seletivo de postos de trabalho: desse modo, os trabalhadores sobreviventes eram em número muito menor e de maior qualificação.

A contraface dessas mudanças exprimiu-se numa ampliação importante dos níveis de desemprego na região, que parece mudar de natureza entre 1989 e 2000 (Gráfico 2).

\section{GRÁFICO 2}

Taxa de Desemprego Total, por Cor e Sexo Região do Grande ABC - 1988-1999

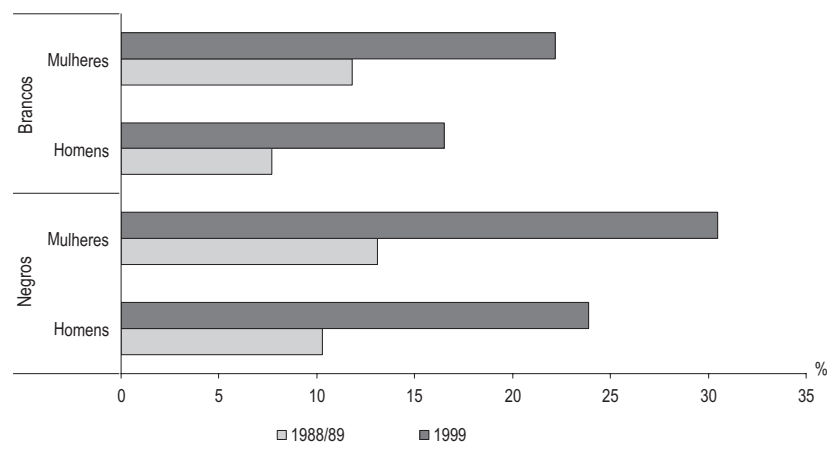

Fonte: SEP; Convênio Seade - Dieese. Pesquisa de Emprego e Desemprego, com apoio do Consórcio Intermunicipal das Bacias do Alto Tamanduatei e Billings. Processamentos próprios.

\section{A DINÂMICA DO MERCADO DE TRABALHO E O PREÇO DOS ATRIBUTOS: PADRÕES DE DESIGUALDADES DE SEXO E COR E ALTERNATIVAS DE POLÍTICAS}

Assinalou-se, até aqui, que um intenso processo de reestruturação ocorreu na região do $\mathrm{ABC}$, alterando o perfil das firmas ali implantadas. No curso desse processo, preservou-se parcela substancial da massa de investimentos, mas alterou-se o padrão da força de trabalho, mudando o perfil dos sobreviventes nos ambientes reestruturados, redefinindo a composição setorial do emprego formal e, sobretudo, ampliando significativamente o volume do desemprego e o risco da exclusão dos espaços tecnológica e organizacionalmente renovados.

Conforme o Gráfico 2, fica patente como, ao longo dos anos 90, o padrão de desemprego se alterou. Tal modificação remeteu as taxas de desemprego aos níveis mais elevados, num movimento que levava de roldão homens e mu- 
lheres, negros e brancos. Entretanto, especificidades devem ser destacadas, posto que o risco do desemprego afetava de maneira desigual os grupos de sexo e cor. Se, em 1989, ele já era mais elevado entre as mulheres, a magnitude dessa diferença se ampliou ao longo da década de 90, de sorte que, em 1999, o problema do desemprego já se manifestava, no ABC, com particular gravidade entre as negras.

Isso nos coloca diante de um segundo tipo de consideração. Quando a atividade produtiva se consolida num contexto de enxugamento fortemente seletivo e de recomposição das oportunidades ocupacionais, quem tem chances de sobreviver e quais trabalhadores passam a estar sob maior risco, merecendo, por isso mesmo, maior atenção das políticas sociais?

É certo que os discursos gerenciais tecem loas à qualificação e a outras características, como o comprometimento com a empresa, a capacidade de trabalho em grupo, a permeabilidade a alvos gerenciais, etc. Entretanto, sabese que desigualdades no acesso ao trabalho nem sempre se fundam em qualidades aquisitivas, podendo estar igualmente baseadas na forma como certos atributos (idade, sexo, cor, etc.) são positiva ou negativamente valorados nos contextos ocupacionais. Disso decorrem diferenças nas chances e no modo de inclusão e nas perspectivas de mobilidade no trabalho.

Sendo assim, não seria descabido indagar como uma recomposição intersetorial do emprego tão intensa se relacionaria com as desigualdades de sexo e cor. Em outras palavras, haveria um problema de inclusão de negros e mulheres nesses novos contextos reestruturados da região? Isto é, diante de um problema tão grave no que concerne ao emprego, como velhas desigualdades passam a se exprimir? Seria possível acreditar que os problemas de acesso, inclusão e mobilidade apresentavam-se de modo distinto entre homens e mulheres, por um lado, e entre negros e brancos, por outro, fazendo com que iniciativas de políticas devessem ser também diferenciadas?

Observando as desigualdades entre sexos no $\mathrm{ABC}$, constata-se que as mulheres ainda pareciam experimentar importantes barreiras em sua inclusão em certos setores da atividade produtiva, com destaque para a indústria de transformação, central na região, que permanecia como um nicho masculino. Entretanto, acompanhadas no tempo, essas barreiras tenderam a refluir, em maior ou menor grau a depender do caso, justamente no curso do período de mais intensa reestruturação das firmas no ABC.

No Gráfico 3 pode-se comparar as razões de mixidade de 1989 e 2000, segundo o setor da atividade econômica.
Vê-se que, à exceção do setor primário (absolutamente irrelevante para o emprego na região), em todos os demais observa-se um refluxo na proporção de homens em relação à de mulheres, inclusive nas indústrias de transformação e de construção civil (nesta última, é certo, permanece residual a presença feminina). Na administração pública, as mulheres chegam mesmo a virar a mesa, passando a liderar o emprego em 2000. E no setor que se tornou o mais importante em termos de provimento de postos formais - os serviços, tanto quando no comércio, tal razão se aproxima de 1 , o que já indicaria um equilíbrio nas chances entre homens e mulheres.

\section{GRÁFICO 3}

Razão entre a Participação de Homens e Mulheres, por Setor Econômico Região do Grande ABC - 1989-2000

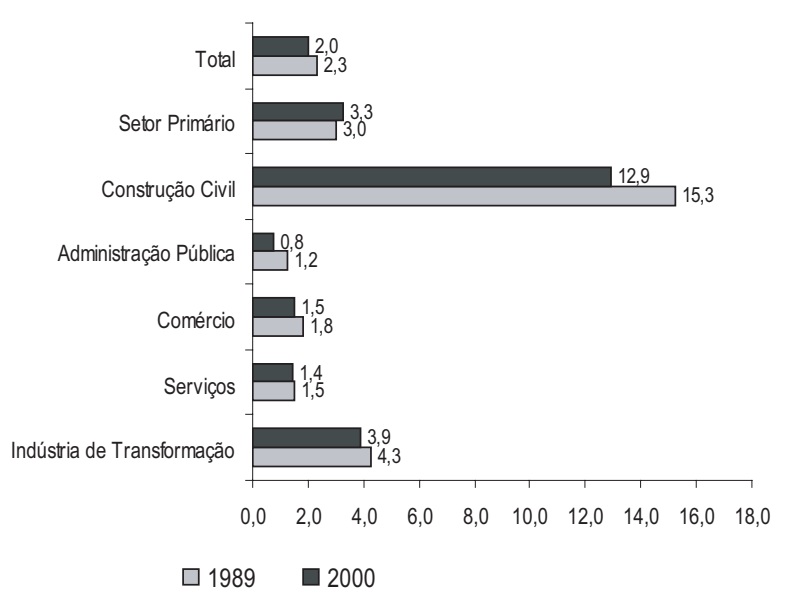

Fonte: MTE. Rais. Processamentos próprios.

Comparadas tais tendências ao que se observa no Brasil, constatam-se algumas diferenças não desprezíveis, que tipificam o que se passa no $\mathrm{ABC}$. Na indústria, os ganhos de inclusão de mulheres foram ainda mais rápidos no $\mathrm{ABC}$ do que na média brasileira, notadamente na construção civil. Todavia, quando se observa a indústria de transformação, ela é muito mais seletiva na região em estudo do que no Brasil como um conjunto; vale dizer, as indústrias que estão sediadas na região são bem menos afeitas que a média brasileira à incorporação de mulheres (a razão de mixidade é quase o dobro no $\mathrm{ABC}$ ), embora tal resistência pareça estar em refluxo. Em compensação, no que tange aos serviços e ao comércio, a situação de inclusão das mulheres é mais favorável na região do que na média nacional.

Ressalta-se, entretanto, que os dados da Rais até aqui utilizados ainda não permitem fazer igual exercício com- 
parando os grupos raciais. E qual a importância de fazêlo? Sabe-se, com os estudos sobre desigualdades de gênero, ${ }^{10}$ que os problemas de inclusão se situam nas diferenças que se expressam entre as mulheres, diferenças estas que se mostram mais importantes hoje (em muitos aspectos centrais) do que as dissimilitudes que se expressam entre os sexos. Vale dizer, a origem social das mulheres pode ser um divisor de águas para o acesso e a mobilidade no trabalho, com resultados tão ou mais importantes do que aqueles produzidos pelas dessemelhanças que as separa dos homens. Por isso mesmo, a observação das tendências do emprego também segundo grupos raciais aporta elementos esclarecedores com respeito ao entendimento do processo de produção das desigualdades, dos seus fatores explicativos no Brasil contemporâneo e das possíveis indicações para iniciativas de políticas.

Assim, prossegue-se tendo como base os dados domiciliares da Pesquisa de Emprego e Desemprego - PED, únicos que permitem, numa análise intrametropolitana, ${ }^{11}$ perseguir a indagação sobre os padrões e os determinantes das desigualdades de sexo e de cor, no trabalho e no desemprego, no curso desses anos de intensa reestruturação do tecido produtivo regional.

Os dados da PED serão analisados visando responder duas questões. Primeira: é possível considerar a existência de problemas de inclusão de negros e mulheres na região e que tais problemas possam estar afeitos às políticas públicas de âmbito local? Segunda: qual a origem dos mesmos? São desigualdades sociais mais amplas que apenas se expressam no mercado de trabalho e, portanto, não requerem, para sua ultrapassagem, medidas de política pública que atuem no âmbito das relações de trabalho? Ou, ao contrário, são discriminações que têm sua origem na operação do próprio mercado de trabalho, que desigualaria as chances de acesso, remuneração e mobilidade dos indivíduos, segundo atributos de sexo e cor, demandando a intervenção dos atores do trabalho? Ou se trata de uma combinação de ambos os tipos de problemas e, com isso, atores do trabalho e gestores públicos estariam instados a atuar com o intuito de corrigi-los?

Parte-se dos padrões de inclusão no mercado de trabalho. No que concerne à oferta de força de trabalho, encontram-se tendências similares às já observadas no Brasil. As taxas de participação eram mais elevadas entre as mulheres negras em 1988-89. Ao longo do período 1988 a $1999,{ }^{12}$ cresceu a participação tanto de negras como de brancas, muito embora seja mais rápido o crescimento do número de brancas no mercado de trabalho. Comparando os sexos, as taxas de atividade são bem mais elevadas entre os homens, sejam eles brancos ou negros. Mas, ao longo do período, há um movimento masculino de passagem à inatividade, que se expressa entre negros e brancos, destacando-se a queda mais pronunciada nas taxas de atividade dos homens negros.

Uma vez no mercado de trabalho, as chances de estar ocupado são desiguais no tempo e entre grupos de sexo e cor. Elas se reduzem para todos, comparando o início da década com o final. Entretanto, as taxas de ocupação são mais baixas entre negros do que entre brancos, e entre mulheres do que entre homens. Vale observar, contudo, que as mulheres brancas, ao longo da década, logram ultrapassar os homens negros no acesso à ocupação e aumentam a distância com relação às mulheres negras. Entre estas últimas parece residir o principal problema de acesso ao trabalho. Isso se confirma se observados os dados de tempo médio de permanência no emprego: é o menor entre as negras; no pólo oposto estão os homens brancos. Entretanto, há uma outra informação que o Gráfico 4 indica: os que sobrevivem, rotam menos, tendendo a permanecer nos postos, mais nos anos 90 que nos anos 80, o que corrobora o observado na seção anterior.

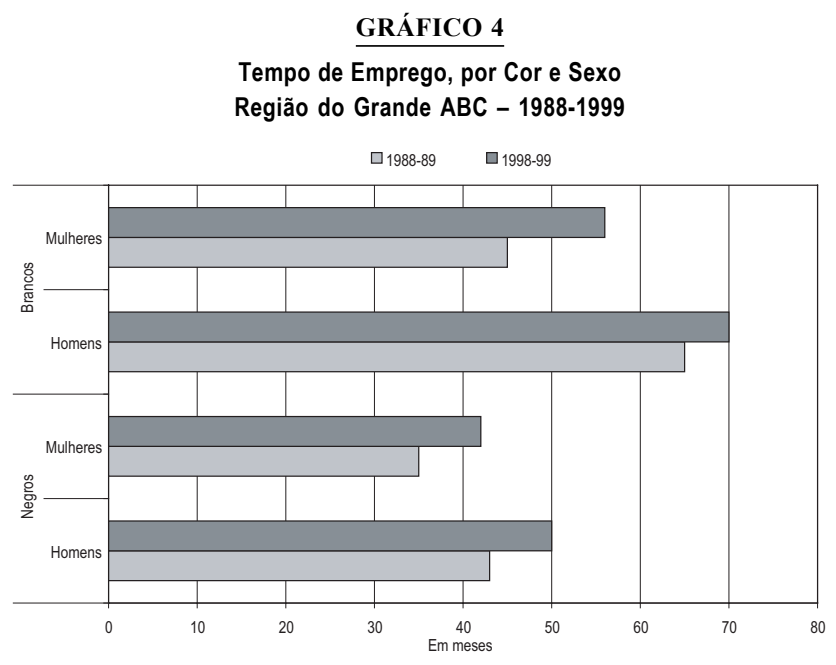

Fonte: SEP. Convênio Seade - Dieese. Pesquisa de Emprego e Desemprego, com apoio do Consórcio Intermunicipal das Bacias do Alto Tamanduatei e Billings. Processamentos próprios.

Sobreviver nos postos de trabalho não é, contudo, a última das barreiras. Uma vez ocupado, o indivíduo deve enfrentar as desigualdades salariais - e este ponto parece ser o calcanhar-de-aquiles no que concerne às discriminações de sexo e cor no Brasil e também na região do $\mathrm{ABC}$.

Uma análise da estrutura dos rendimentos reais, segundo grupos de sexo e cor, sugere claramente a existência de 
um hiato significativo a diferenciar os grupos. Quanto desse hiato resulta efetivamente de discriminação - de tipo racista ou sexista - exercida no âmbito do trabalho? Quanto resulta de diferenciais de qualificação (escolaridade ou experiência) ou outros atributos do trabalhador (como ser ou não migrante) e que podem expressar desigualdades sociais mais amplas (no acesso à escolarização de qualidade, por exemplo), desaparelhando-o no que tange ao salário? Finalmente, quanto dessa diferença resulta de características outras que depreciam o preço da sua força de trabalho (mas que nada têm com racismo ou sexismo), como podem ser o padrão de remuneração que resulta do setor em que se insere o trabalhador, ou tipo de ocupação (posição na hierarquia ocupacional), ou natureza do vínculo de trabalho (se formalizado ou não). Para controlar esses possíveis determinantes da diferença de salários, utilizou-se um modelo especial de análise de regressão. ${ }^{13}$ Nele, os determinantes da variação dos salários dos grupos mais mal remunerados (mulheres brancas, homens negros e mulheres negras) são decompostos de modo a identificar o quanto explicam da diferença que separa cada um desses grupos do padrão de remuneração média daqueles que ganham os mais altos salários (no caso, os homens brancos).

O Gráfico 5 permite formular algumas conclusões que, embora parciais, não deixam de ser interessantes do ponto de vista de uma reflexão sobre políticas públicas.

Primeira e mais importante delas: distintos fatores explicam as desigualdades salariais de homens negros, mulheres brancas e mulheres negras, vis-à-vis os homens brancos. Ou seja, se há desigualdade, ela ganha corpo, em cada caso, por meio de padrões explicativos distintos. No caso dos homens negros, a distância salarial em face dos brancos resulta, sobretudo, de um diferencial de qualificação escolar; embora a condição racial tenha alguma capacidade explicativa (vide a coluna "segregação"), é na coluna “qualificação" que se encontra o mais importante fator determinante dos seus baixos salários (quase $70 \%$ da distância que os separa dos homens brancos se explica por esse fator). Ou seja, para os homens negros torna-se vital que os poderes públicos, locais e supralocais, disponibilizem acesso a níveis mais elevados de educação escolar de qualidade, como forma de combater sua desvantagem salarial.

No caso das mulheres negras, um mix ainda maior de fatores mostra-se determinante da sua grande desvantagem salarial. Há um problema de qualificação escolar que, embora menor que o dos homens negros, se mostra o mais importante fator. Muito próximos em capacidade explicativa, há problemas quanto ao que se denomina “inserção formal”, fator que mede a sujeição a relações precárias de trabalho (no caso, muito provavelmente devido ao peso significativo que tem, entre elas, o emprego doméstico). Finalmente, destacam-se nesse cardápio de desvantagens a sua inserção em posições subalternas nas hierarquias ocupacionais, o que lhes acarreta menor remuneração, e aquilo que poderia ser atribuído à discriminação racial e sexual (ou seja, há uma parcela do salário que apenas se explica pela condição racial e de sexo, parcela esta expressa no fator denominado, no Gráfico 5, como "segregação"). Ora, no caso das mulheres negras, estamos claramente diante de uma situação em que se acumulam as desvantagens: algumas resultam de desigualdades sociais mais profundas e que requerem a incursão dos gestores locais (acesso à escolarização em níveis mais elevados); outras resultam da necessidade de maior proteção ou melhor regulação de relações precárias de trabalho, envolvendo gestores públicos e atores privados no âmbito do trabalho; outras, enfim, demandam vigilância e controle dos trabalhadores, sindicatos e gerências sobre a permeabilidade dos executores das políticas de remuneração e promoção a critérios particularistas e de tipo discriminatório.

Finalmente, o caso das mulheres brancas é exemplar de uma situação em que a trabalhadora logrou a escolari-

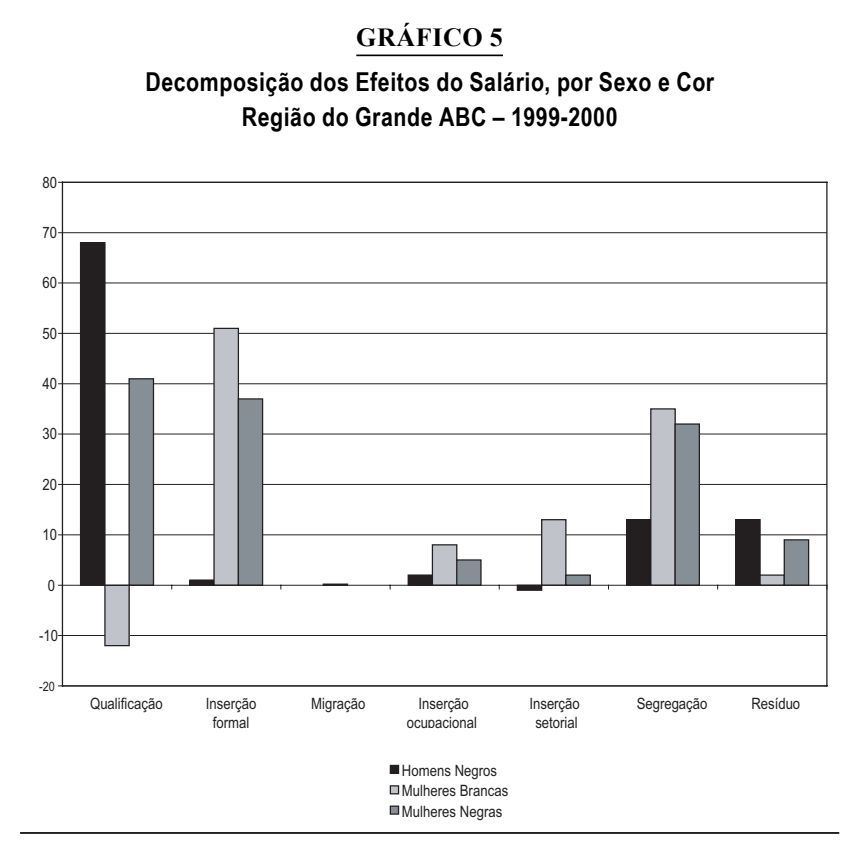

Fonte: SEP. Convênio Seade - Dieese. Pesquisa de Emprego e Desemprego, com apoio do Consórcio Intermunicipal das Bacias do Alto Tamanduatei e Billings. Processamentos próprios. 
zação que a eqüidade salarial lhe permite (notar como a expressão negativa do fator, no Gráfico 5, indica de modo eloqüente que elas, em média, recebem muito menos do que aquilo que a sua escolarização lhes facultaria). Entretanto, a inserção em formas precárias de relações de trabalho e a discriminação de sexo (que é determinante nesse mais do que em qualquer outro grupo) constituem os fatores que mais explicam a defasagem salarial que as distingue dos homens brancos. Entre elas, são justamente os fatores produzidos na operação do mercado de trabalho que melhor explicam as suas desvantagens salariais. E, nesse caso, políticas envolvendo poder público e gestores de empresas em muito poderiam melhorar os problemas de eqüidade a que as brancas estão sujeitas.

Mas há uma segunda ordem de considerações que se pode extrair do Gráfico 5: por mais que variem os determinantes do hiato nos rendimentos para cada um dos grupos com menores salários, há - em todos eles - a prevalência de um fator promotor de desigualdade que não se explica por outra razão que não a condição de sexo e/ou racial. Ou seja, quando se controlam todos os demais fatores (escolaridade, idade, posição na hierarquia ocupacional, tipos de inserção setorial, condição migratória, existência de vínculo precário) resta uma parcela da desigualdade salarial que só se explica por atributos pessoais como sexo e cor, que não deveriam determinar - caso houvesse eqüidade de gênero e raça - o preço do trabalho. Se apenas dispuséssemos de dados convencionais, que mostram as meras distâncias salariais entre homens e mulheres, negros e brancos, diríamos, como é corrente, que as mulheres negras eram o grupo mais desprivilegiado, para o qual a discriminação sexual e racial mais atuaria deprimindo salários. Com a análise mais refinada e as estatísticas mais robustas que sustentam o Gráfico 5, pode-se dizer que elas, tanto quanto os homens negros, testemunham como se acumulam desvantagens (sociais e ocupacionais) que explicam os salários desiguais. Mas, em todos os casos, fica patente que há um problema de eqüidade de gênero e raça entre os que logram ingressar e permanecer ocupados; esse problema pode ter um peso mais expressivo (caso das mulheres brancas), ou aparecer de modo secundário ao lado de outros determinantes igualmente ponderáveis (caso dos homens brancos e das mulheres negras).

Ocorre, contudo, que nem todos logram sobreviver nos postos de trabalho. Tal como sublinhado anteriormente, no $\mathrm{ABC}$, nos anos 90, o desemprego amplia significativamente seu volume, e as chances de ocupação se restringem. E, nesse caso, como se expressam as desigualdades de sexo e cor? Quando se analisa o outro segmento do mercado de trabalho, onde se alojam os que perderam a ocupação, destaca-se de imediato o crescimento do tempo médio de procura de trabalho.

$\mathrm{Na}$ região do $\mathrm{ABC}$, isso se faz de modo impressionante e generalizado (Gráfico 6), documentando as dificuldades de obtenção de trabalho ao longo da década, obstáculos que afetam todos os que perderam seus empregos, quase que independentemente de sexo e cor. É a evidência da enorme seletividade no que concerne aos bons postos, aqueles com carteira assinada.

O crescimento do tempo médio de procura de trabalho é corroborado pelo crescimento do tempo médio de desemprego. Este também aumenta de modo significativo. Mas quem são os trabalhadores particularmente afetados por esse aumento? As mulheres, sejam elas brancas ou negras. Para elas, o crescente tempo de procura de trabalho, na maioria das vezes, não promove a ocupação; ao contrário, ele se expressa num tempo de permanência no desemprego que é muito maior que o dos homens. Ou seja, o risco do desemprego é muito mais feminino que masculino.

\section{GRÁFICO 6}

Tempo Médio de Procura de Trabalho, por Cor e Sexo Região do Grande ABC - 1988-1999

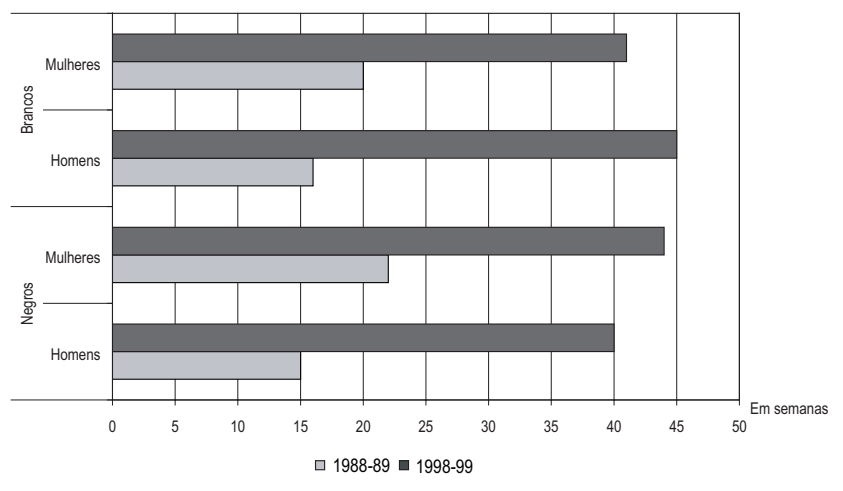

Fonte: SEP. Convênio Seade - Dieese. Pesquisa de Emprego e Desemprego, com apoio do Consórcio Intermunicipal das Bacias do Alto Tamanduatei e Billings. Processamentos próprios.

E esse risco não está livre de conseqüências na medida em que a permanência continuada no desemprego inabilita o trabalhador (no caso, a trabalhadora) aos benefícios do sistema público, como o seguro-desemprego. O mesmo se dá quando a inserção se faz em atividades precárias, sem carteira assinada, o que também é mais comum entre as mulheres. Ou seja, são justamente as mais sujei- 
tas ao desemprego e à precarização aquelas que menos se habilitam aos beneficios do sistema público de proteção (COMIN; GUIMARÃES, 2000).

Ademais, a perda do emprego e o tempo de permanência no desemprego promovem um processo de instabilidade ocupacional que aumenta as dificuldades de reinserção, comprometendo as chances de empregabilidade. No dizer de Demazière (1995, p. 52), o desemprego acaba servindo como um mecanismo de redistribuição dos empregos.

Diante de um movimento de tão intensa mobilidade, seja entre ocupações, seja entre desemprego e ocupação, seja entre desemprego e inatividade, caberia afastar uma última possibilidade e verificar a hipótese contrária ao argumento aqui defendido, ou seja, de que há lugar para políticas públicas voltadas para eqüidade de gênero no âmbito regional. Que hipótese seria essa? A de que, premidos pelo trânsito ocupacional, forçados pelo enxugamento intenso promovido pelas firmas, os trabalhadores deixassem de ter na região do $\mathrm{ABC}$ o seu espaço por excelência de busca de trabalho.

E por que se faz necessário afastar essa hipótese alternativa? Porque as iniciativas de política de eqüidade, que mobilizem atores sociais e gestores locais, supõem que os problemas diagnosticados no $\mathrm{ABC}$ possam ser atacados por meio de políticas públicas de vigência e efeitos igualmente fecundos no âmbito regional. Isso requer que os trabalhadores em mobilidade tenham nesse espaço regional o seu ponto de referência para solução dos problemas ocupacionais, de inclusão e eqüidade no trabalho.

Acompanhou-se, então, a base de dados Rais-Migra. ${ }^{14}$ Ela permitiu observar dados sobre todos os trabalhadores ocupados no mercado de trabalho do ABC em 1994 e buscou-se verificar onde os mesmos se encontravam em 1998. Ou seja, indagou-se se haveria uma mobilidade espacial correlata à intensa transição ocupacional, que pusesse em risco a existência de um mercado de trabalho passível de ser atingido por políticas de corte regional.

Notou-se, então, que dos cerca de 600 mil trabalhadores que estavam ocupados no $\mathrm{ABC}$ em 1994, 70\% deles ainda se encontravam com vínculo formal e podiam ser localizados pelo sistema Rais em 1998. Desses, nada menos que $76 \%$ permaneciam em atividades no $\mathrm{ABC} ; 16 \%$ haviam se deslocado para outros municípios da Região Metropolitana de São Paulo e um resíduo para a capital.

Para finalizar, isso permite intuir que:

- problemas de inclusão e eqüidade se manifestam na região do $\mathrm{ABC}$ no curso do recente processo de reestruturação do tecido produtivo;
- tais problemas afetam os trabalhadores, notadamente negros e mulheres, que têm na região do Grande $\mathrm{ABC}$ o mercado de trabalho por excelência, onde disputam posições ocupacionais;

- tais problemas são passíveis da intervenção seja no plano das políticas públicas de tipo universalista e de inclusão (notadamente as políticas de elevação da escolaridade), seja no plano das políticas focalizadas no mercado de trabalho (com destaque para as políticas de proteção ao trabalho e de preservação de direitos), seja no plano das empresas e da sua gestão de pessoal (com destaque para políticas de contenção dos fatores de discriminação, notadamente operantes no plano da remuneração e das carreiras);

- a riqueza do tecido institucional e da rede de atores e gestores que existe no Grande $\mathrm{ABC}$ pode fazer da região um laboratório de iniciativas frutíferas de políticas públicas voltadas à eqüidade.

\section{NOTAS}

Agradeço o apoio técnico de Edna Yukiko Taira, Flavia Luciane Consoni, Paulo Henrique da Silva e Marcus Vinicius Farbelow, na preparação dos dados utilizados na análise. Uma versão mais longa (e, por isso mesmo, melhor documentada) do argumento que aqui se apresenta pode ser encontrada em Guimarães (2003, p. 20-39, cap. 2).

1. Trata-se do projeto Fapesp/Políticas Públicas n. 98/14-0448 "Gestão Local, Empregabilidade e Eqüidade de Gênero e Raça. Um Experimento de Política Pública na Região do ABC Paulista", cuja montagem e coordenação foi de co-responsabilidade da autora e que se desenvolveu com apoio do Programa de Pesquisas em Políticas Públicas da Fundação de Amparo à Pesquisa do Estado de São Paulo - Fapesp. $\mathrm{O}$ projeto mobilizou uma equipe interinstitucional, integrando o Centro Brasileiro de Análise Planejamento - Cebrap, a Prefeitura Municipal de Santo André, o Centro de Estudos das Relações de Trabalho e Desigualdades - Ceert e o Elisabeth Lobo Assessoria, Trabalho e Políticas Públicas - Elas. Desenvolvido entre 1999 e 2002, o relatório final veio à luz em 2003.

2. Assim, por exemplo, sindicatos passam a intervir diretamente em âmbitos de regulação do mercado de trabalho até então privativos da ação governamental (como o agenciamento de colocação para trabalhadores desempregados), ou, quando muito, acessíveis à parceria com instituições corporativas de origem empresarial (como os programas de qualificação profissional, estreitamente vinculados ao chamado "Sistema S").

3. Usando os termos do final dos anos 90 , quando iniciou-se o estudo, tais políticas buscaram resistir à chamada "guerra fiscal", como foi nomeado o grande desafio tornado público nesse momento no $\mathrm{ABC}$ e em torno do qual formou-se uma sorte de consenso, não apenas "nativo", mas igualmente analítico.

4. Para uma mais cuidadosa discussão desse argumento, ver Guimarães e Martin (2001, p. 11-29).

5. Para uma discussão mais detida das características desse rico tecido institucional e das novidades empreendidas pelos atores lo- 
cais, ver: Guimarães, Comin e Leite (2001, p. 417-447), Arbix (1996) e também Leite (2003).

6. Devido à própria história da indústria e das relações de trabalho na região, o emprego formal sempre teve ali maior importância que na média do mercado de trabalho brasileiro.

7. Sobre os resultados da Pesquisa da Atividade Econômica Paulista - Paep (levantamento idealizado e conduzido pela Fundação Seade, inicialmente realizado em 1996) e seus achados a respeito do tema da estrutura e concentração da atividade econômica, ver Matteo e Tapia (2003, p. 3-19, cap. 1).

8. De fato, tal participação se manteve estável nos 15 anos que antecederam a pesquisa (se alinhados os dados do Seade e do IBGE).

9. É significativo que a Paep tenha indicado que as taxas de inovação tecnológica das empresas do ABC fossem, em 1996, significativamente maiores que nas demais regiões do Estado, aí compreendida a própria Região Metropolitana de São Paulo. Ver: Agência de Desenvolvimento Econômico do ABC (2000); Matteo e Arbix (2001, p. 211-229).

10. Ver: Lavinas (1998); Bruschini (2000, p. 13-18); Bruschini e Lombardi (2000, p. 67-104); Leme e Wajnman (s.d.); Soares (2000); Biderman e Guimarães (2002); Guimarães (2001, p. 2002: 237-266).

11. Graças à existência de uma amostra ampliada para o $\mathrm{ABC}$, representativa da sua população economicamente ativa.

12. Doravante, nesta seção, os dados relativos à PED - ABC estarão somados em períodos de dois anos, dada a necessidade de se acumular uma massa de unidades de observação suficiente para controlar simultaneamente diversas variáveis. Os anos escolhidos prestam-se ao artifício da agregação, posto que não apresentam significativas diferenças intraperíodo.

13. Trata-se do método de decomposição de Oaxaca, já utilizado para dados brasileiros e cuidadosamente descrito por Soares (2000); Leme e Wajnman (s.d.); Biderman e Guimarães (2002) e Guimarães (2002).

14. Base de dados especialmente produzida para a pesquisa pela Datamec, mediante autorização do Ministério do Trabalho e do Emprego, que facultou acesso aos cadastros Rais-Caged, londitudinalizados, para montagem de um painel de transições ocupacionais no mercado formal do ABC entre 1994 e 1998. Agradeço a essas instituições pelo inestimável apoio.

\section{REFERÊNCIAS BIBLIOGRÁFICAS}

AGÊNCIA DE DESENVOLVIMENTO ECONÔMICO DO ABC. A atividade econômica nos anos 90 no ABC. Reestruturação e inovação na indústria. Cadernos de Pesquisa, Santo André, n. 2, 2000 .

ARBIX, G. Uma aposta no futuro. São Paulo: Scritta, 1996.

BIDERMAN, C.; GUIMARÃES, N.A. Desigualdades, discriminação e políticas públicas: uma análise a partir de setores selecionados da atividade produtiva no Brasil. Comunicação apresentada na II INTERNATIONAL CONFERENCE ILAS-CEBRAP, 18-20 mar. 2002, São Paulo, 30 p.

BRUSCHINI, C. Gênero e trabalho no Brasil: novas conquistas ou persistência da discriminação? (Brasil, 1985-1995). In: ROCHA, M.I.B da. (Org.). Trabalho e Gênero - Mudanças, permanências e desafios. São Paulo: Editora 34, 2000. p. 13-18.

BRUSCHINI, C.; LOMBARDI, M.R. A bipolaridade do trabalho feminino no Brasil contemporâneo. Cadernos de Pesquisa, São Paulo, Fundação Carlos Chagas, n. 110, p. 67-104, jul. 2000.
COMIN, A.; GUIMARÃES, N.A. Mobilidade setorial, diversidades de gênero e acesso ao seguro-desemprego: vicissitudes do trabalho no Brasil nos anos 90. Comunicação apresentada no painel "Sustentabilidad social del crecimiento econômico em América Latina: Repensando las políticas de empleo". IN: LASA, XXII CONGRESSO INTERNACIONAL, 16 mar. 2000. Miami, $30 \mathrm{p}$.

DemaZiÈre, D. Le Chômage de Longue Durée. Paris: Presses Universitaires de France, 1995.

GUIMARÃES, N.A. Reestruturação, mercado de trabalho e desigualdades de gênero e raça. In: GUIMARÃES, N.A. et al. Gestão local, empregabilidade e eqüidade de gênero e raça: um experimento de política pública no ABC. São Paulo: Cebrap, 2003. p. 20-39, cap. 2. (Relatório Final do Projeto Fapesp 98/14-0448).

Os desafios da eqüidade: reestruturação e desigualdades de gênero e raça no Brasil. Cadernos Pagu, Campinas, v. 17/18, p. 237-266, 2002 .

Laboriosas, mas redundantes: gênero e mobilidade no trabalho no Brasil dos anos 90. Estudos Feministas, v. 9, n. 1, 2001.

GUIMARÃES, N.A.; MARTIN, S. Descentralização, eqüidade e desenvolvimento: atores e instituições locais. In: __ (Org.) Competitividade e desenvolvimento: atores e instituições locais. São Paulo, Senac, 2001. p. 11-29.

GUIMARÃES, N.A.; COMIN, A.; LEITE, M. Por um jogo de soma positiva: conciliando competitividade e proteção ao emprego em experiências inovadoras de negociação no Brasil. In: GUIMARÃES, N.A.; MARTIN, S. (Org.). Competitividade e desenvolvimento: atores e instituições locais. São Paulo: Senac, 2001. p. 417447.

LAVINAS, L. Diferenciais de rendimentos entre homens e mulheres nas áreas metropolitanas. Rio de Janeiro: 1998. 18p. Mimeografado.

LEITE, M. Trabalho e sociedade em transformação. Mudanças produtivas e atores sociais. São Paulo: Fundação Perseu Abramo, 2003.

LEME, M.C. da S.; WAJNMAN, S. Tendências de coorte nos diferenciais de rendimento por sexo. São Paulo. [s.d.] 18p. Mimeografado.

MATTEO, M.; ARBIX, G. A teimosia da indústria paulista. In: SANTOS, A. et al. (Org.). Anos 90: Um olhar sobre as políticas de industrialização no Estado de São Paulo. São Paulo: Ed. Humanitas/ FFLCH-USP, 2001. p. 211-229. (Coleção Primeiros Estudos, n. 1).

MATTEO, M.; TAPIA, J. A reestruturação da indústria paulista e o ABC. In: GUIMARÃES, N.A. et al. Gestão local, empregabilidade e eqüidade de gênero e raça: um experimento de política pública no ABC. São Paulo: Cebrap, 2003. p. 3-19, cap. 1. (Relatório Final do Projeto Fapesp 98/14-0448).

SOARES, S.S.D. O perfil da discriminação no mercado de trabalho. Homens negros, mulheres brancas, mulheres negras. Rio de Janeiro, Ipea, nov. 2000. (Texto para discussão, n. 769).

Nadya Araujo Guimarães: Professora Livre-Docente do Departamento de Sociologia da Universidade de São Paulo e Pesquisadora do Cebrap (nadya@uol.com.br). 